\title{
Linking alternative food networks and urban food policy: a step forward in the transition towards a sustainable and equitable food system?
}

DOI 10.1515/irsr-2016-0007

Received: March 8, 2016; Accepted: April 29, 2016

\begin{abstract}
Seen as a response to the incumbent crisis affecting the food system, alternative food networks are a promising link of a new food chain, founded on a sustainable paradigm. Their activities aim at realizing a process of 're-localization' and 're-socialization' of food productiondistribution-consumption practices, holding a prospect for the construction of a more environmentally sound, socially just and economically sustainable local food system. In order to provide such benefits, though, a host of regulatory constraints and logistical and operational barriers have to be overcome. In this paper we argue that a potentially effective force supporting the development of alternative food networks is detectable in the rapidly diffusing trend constituted by the adoption, by local governments, of a set of urban food policies integrating food issues into the many spheres of urban regulation. Such policy effort may help to coordinate public intervention with the purpose of setting the ground for a healthy local/regional food system, and provide alternative food networks with stronger connections, political capital and legitimization.
\end{abstract}

Keywords: Alternative food networks; urban food policy; food system; food crisis; sustainability; food security.

\section{Introduction}

In recent years, both academics and institutions have recognized the emergence of a 'food crisis', enrooted in a capitalistic, corporate-led and commodified food system (see, for example: FAO, 1997; IAASTD, 2009; Lee and Stokes,

\footnotetext{
*Corresponding author: Raffaele Matacena, Department of Sociology and Social Research, University of Milan-Bicocca, U7 Building, Via Bicocca degli Arcimboldi 8, 20126 Milan, Italy, E-mail: r.matacena1@campus.unimib.it
}

2009; Godfray et al., 2010; Sage, 2011; Almås and Campbell, 2012; Spaargaren et al., 2013; Maye and Kirwan, 2013). Modern food production-consumption regime has developed around ideas of productivism (Marsden and Morley, 2014), profit-seeking, global supply and resource exploitation, and has caused a series of externalities and impacts on the social, economic and environmental scenarios that now seem to have reached a critical threshold. A multitude of analysts agree that the 'world of food' we are entering requires immediate intervention, to correct the current food system trajectory. Current food regime is bringing agriculture to become the least relevant part of a gigantic industrial mechanisms managed by a small number of powerful corporations. It is causing the depletion of soils, water and biodiversity to reach an irrecoverable degree. It is witnessing, both in the global North and South, not only the growth of inequalities in accessing sufficient, fresh and healthy food, but also the growing epidemic of (mal)nutrition-related illnesses, such as obesity, diabetes and heart diseases.

The need for a renewed model, i.e. the urgency to build a sustainable paradigm within which to insert (not only) the food system is therefore becoming the common denominator of many political and economic programs. Yet, the very same concept of sustainability is contested and complex, and a radical transformation of food-related activities and practices will require a huge and multiscalar effort toward redirecting norms, (social and economic) behaviors and routines, and governance goals. It will also involve challenging consolidate interests and global power structures.

Under these lights, the emergent phenomenon of alternative food networks (AFNs) is conceptualized as holder of transformative potential towards a more just, equal and sustainable food system. Through a process of re-embedding, both in a social and a spatial sense, of food production, distribution and consumption practices, such networks are seen as able to promote a more profound change in the food scenario, that passes through the establishment of a local food system which 
enhances the role of small and family farmers who employ environmentally sound methods, and facilitates the construction of a more direct relationship between these and the consumers (especially urban). To express such potential, though, a number of barriers and inconsistencies has to be overcome, that may obstruct the scaling-up and convergence tracks of alternative food networks. Addressing this issue, a facilitating instrument is detected in the adoption of urban food policies, a tool that many cities all over the world are currently equipping themselves with and that aims at integrating food issues into the many spheres of urban regulation. Urban food policy councils and urban food strategies may help to coordinate public intervention with the purpose of setting the ground for a healthy local/regional food system, and provide alternative food networks with stronger connections, political capital and legitimization. In the following sections, we will present the characteristics and the debates concerning alternative food networks and urban food policy, and provide insights about their actual and potential interlinkages.

\section{Alternative food networks}

Analyzing the food system, Moya Kneafsey and her colleagues (2008) focus on the issue of 'disconnection', regarded as one of the negative consequences of the predomination of capitalistic corporate forces in the food provisioning chain:

'Many of the problems regarding the food system are attributable, at least partly, to the disconnections of consumers from food, in the sense that many consumers know very little about where much of their food come from, what it is made of, how it is produced, and by whom' (ibid., p. 5).

This increasing gap, which is cultural and spatial, between production and consumption generates a series of implications, both for the producers and the consumers. The former suffer from a decrease in economic relevance (and income), tied to a loss of autonomy and capability of using traditional and inherited knowledge-practices about land and livestock, and a consequent disappearance of traditional knowledges, memories and stories associated with nature. The latter's lack of knowledge and reduced ability to judge generates anxieties in the relationship with food, especially since consumers are called to choose from an ever larger range of foods, while the neoliberal setting in which they act often causes social disadvantages to degenerate into difficulties in accessing healthy food (ibid.).

As a response to the 'disconnecting' track globalized food follows, a great number of initiatives centered on experimenting different models of food provisioning have sprawled throughout the world, the common nature of which is referred to with the umbrella term 'alternative food systems' (or networks, AFNs). The denomination refers to a wide variety of rapidly diffusing initiatives and schemes of food provisioning that express a sense of differentiation from, and to some extent counteraction to, mainstream modes which dominate the conventional ${ }^{1}$ food system.

They are generally organized to 're-socialize' (Kneafsey etal., 2008; Goodman et al., 2012; Sage, 2011) and 're-localize' food (Hinrichs, 2003; Mount, 2012). Re-socialization rests upon bringing food out of the highly individualized fashion in which consumers make personal choices within the wide range offered by supermarkets and other corporate retailers, and more fully into the civic arena where public goods issues are given weight and consideration (Sage, 2011). It operates by building relations and promoting stronger connections among a whole set of food-related actors, not limited to producers and consumers but also comprising restauranteurs, food writers, grassroots food movements, civil society organizations, consumer co-ops and social entrepreneurs, all to some degree engaged in finding a way out of the more standardized patterns of conventional food supply.

Re-rooting food in a specific place is the strategy employed in pursuing such alternative provision models. Food re-localization is practiced whether through production, processing, retailing and consumption all taking place within a prescribed area (as in the case of short chains, farmers' markets ${ }^{2}$, community supported agriculture $^{3}$, box schemes ${ }^{4}$, solidarity-based purchasing

1 With 'conventional' or 'mainstream' food system we denote the types of food production and distribution which have come to dominate the market, and that manifest a heavy reliance on industrialized methods of food production and processing, global sources and means of supply, corporate modes of financing and governance, and an imperative towards operational efficiency (Tregear, 2011).

2 Markets where food is sold directly by its producers.

3 Community supported agriculture exists when a community of individuals pledge support to a farm operation, so that growers and consumers provide mutual support and share the risks and benefits of the growing activity. Commonly, the members of the community cover in advance the anticipated costs of the farm operation and farmer's salary. In return, they receive shares of the farm production regularly throughout the growing season, usually through a periodic fresh food box scheme. In addition to the risk reduction, thanks to such initiatives growers receive better prices for their crops, gain some financial security, and are relieved of much of the burden of marketing.

$4 \mathrm{~A}$ box scheme is an operation that delivers fresh fruit and vegetables, often locally grown and organic, either directly to the customer or to a local collection point. Typically the produce is sold as an ongoing weekly subscription and the offering may vary week to week depending on what is in season. 
groups $^{5}$, food hubs ${ }^{6}$, urban agriculture, community gardens ${ }^{8}$ ), and/or through the exchange of products which embody the natural and/or cultural characteristics of a particular area, even if retailed or consumed far outside the production area (for example, organic agriculture, terroir and specialty products, craft products, products with denomination of origin, fair trade products ${ }^{9}$ ) (Tregear, 2011). In both cases, these traits of embeddedness of food products into peculiar places and ecologies act to contrast the perceived rootless nature characterizing the conventional system and its outputs.

AFNs are gaining vibrancy, membership and participation, as well as sparking academic interest, for they are seen as creating, in a varied and multifaceted way, new spatial and social connections which can pave the way to the construction of a real sustainable food paradigm, founded on the renewal of linkages in and across urban and rural spaces, and on the capsize of our established spatial theories and supply chain models (Feagan, 2007; Allen, 2010, Marsden and Morley, 2014). In a context framed by food security and sustainability crises, these networks' response is directed to ultimately empower both the 'urban food consumer' to become a more knowledgeable producer of its own and its family's health and well-being (Roberts, 2008), and the 'rural producer' to become a multifunctional provider of sustainable goods and services for rural and urban groups (Franklin and Morgan, 2014).

5 Solidarity-based purchasing groups are defined as those non-profit associations set up to carry out collective purchase of foods and distribution thereof, without application of any charge to members, with ethical purposes, of social solidarity, environmental sustainability and food quality (adapted from the 2007 Finance Act of the Italian Government).

6 A food hub is a business or organization that actively manages the aggregation, distribution, and marketing of source-identified food products primarily from local and regional producers in order to satisfy wholesale, retail, and institutional demand (National Food Hub Collaboration website, visited October 2015).

7 Defined as the use of (intra- and peri-) urban spaces for growing food, feed and ornamental plants, either individually or on a collective or community basis.

8 They are plots of land where groups of citizens work regularly together to propagate agricultural produce for personal or public consumption, both growers and consumers being mostly residents of the neighborhood that hosts the garden.

9 Fair Trade is a trading partnership, based on dialogue, transparency and respect, that seeks greater equity in international trade. It contributes to sustainable development by offering better trading conditions to, and securing the rights of, marginalized producers and workers - especially in the South (World Fair Trade Organization website, visited October 2015).

\section{Potential and shortcomings of AFNs}

A vast potential for AFNs to generate an array of beneficial outcomes is significantly highlighted by researchers. The most frequently reported relate to (often overlapping) elements of (positive) local anchorage, economic viability, ecological sustainability, and social justice. Moving towards a localized food system helps primarily to avoid the appropriation of value by distant or transnational companies, revitalizing primary production sectors, especially in peripheral areas (Ilbery et al., 2004). It also offers the potential basis for more collective solutions for community development, enhancing trust and social capital that can spill over into other collective and community initiatives, and provides opportunities for building synergies with other sectors, such as tourism (Sage, 2011).

From an economic standpoint, AFNs viability lies in the possibility for consumers to purchase fresh and healthy food at a reasonable price (Little et al., 2009) which combines, on the producers' side, with enhanced possibilities to increase margins (La Trobe, 2001), stimulate diversification and entrepreneurship (Morris and Buller, 2003) and develop new skills (Brown and Miller, 2008). Furthermore, the wider community may also benefit via multiplier effects and employment generation in non-agricultural sectors (Ilbery et al., 2004). From an ecological perspective, local-based food initiatives generally leverage on organic and environmentally-friendly farming methods and enjoy those ecological gains associated to short supply chain, such as increase of (agro-) biodiversity, reduction of food miles ${ }^{10}$ and carbon emission, thus stimulating progress in the sustainability agenda (Sage, 2011). As per the social justice characteristics of AFNs, researcher argue that the re-building of participants' relations brings the actors into closer proximity and mutual understanding (Kneafsey et al., 2008), generating respect, trust and commitment (Kirwan, 2004), fostering more harmonious community relations and engaging participants into more democratic food provisioning (Goodman et al., 2012).

Despite these many claims, though, even a number of critical points have been raised by AFNs analysts regarding their problematics. For example, in a recent scientific report to the European Commission edited by Santini and Gomez y Paloma (2013), it is argued that the commonly quoted economic and environmental benefits of local food systems are still debated, mainly due to the

10 The distance food travels from where it is grown to where it is ultimately purchased or consumed by the end user. 
lack of reliable qualitative and quantitative indicators of their impacts in current research. Nevertheless, there are other two major shortcomings which are frequently cited in alternative food literature. The first refers to a matter of equity and criticizes AFNs because in some cases their effect is to perpetrate pre-existing social inequalities rather than dismantling them (Goodman et al., 2012; Marsden and Morley, 2014), contrary to what most ideology would suggest. Instead of amplifying the basis for accessing food, to include the disadvantaged and the food poor, many participants come from affluent segments of the society, thus making these initiatives appear more as a product, rather than a driver, of socioeconomic development in a region (Tregear, 2011). Many contributions, though, bring evidence of a more mixed composition of participants' socio-economic provenance (Kneafsey et al., 2008), and reveal a complex scenario which yields out of many different contingencies which should be analyzed with a context-based case by case approach (let's just think about the huge differences that may exist between organic food purchased in a specialized shop and local food provided by a solidaritybased purchasing group).

A second area of criticism regards the notion of 'local'. It is widely acknowledged that research efforts must avoid falling into the 'local trap' of ascribing an inherent desirability to the local (Born and Purcell, 2006), since it is not possible to aprioristically determine that a localized food system will in itself deliver a range of positive outcomes. Re-localization, furthermore, can hide 'defensive localism' attitudes (Winter, 2003) which manifest the conservative desires of a community to defend itself from outside threatening forces rather than adopting an open and inclusive approach to build communitarian, ecologically-sound forms of food provisioning.

Another interesting critical insight is offered by Tregear (2011), who reports of the uncertainties she detects in literature's effectiveness in explaining AFNs' impact on wider economies, and in giving sense of the personal values, motivations, and interaction of practitioners. She underscores a certain research tendency towards conflating alternative food systems' spatial or structural characteristics with specific desirable outcomes, actor behaviors or food properties. In the opinion of the author, such conflations often lead scholars to a priori evaluations of the potential of alternative food provision re-arrangements, thus hiding a more complex reality that is shaped by interrelated socio-political processes, for the understanding of which a plurality of perspectives and a stronger empirical basis are needed.

\section{Alternative versus conventional}

The complexity of AFNs reality also finds an explication in the fact that they do not exist in a separate sphere from the conventional food systems, rather they are deeply embedded in it and depend on the capitalistic market for their social and material reproduction (Goodman et al., 2012). They are not to be seen, as Goodman and his colleagues assert (ibid.), as 'oppositional' in the sense that they seek to overthrow the hegemonic capitalist system. Rather, they interact and co-evolve with the conventional food system and attempt to change it from within, challenging its productivity-driven socio-spatial arrangements by creating alternative economic spaces within which to develop different operational logics and value systems.

As all economic geographies, AFNs are constrained by the requirements of materially effective circuits of consumption, exchange and production (Leyshon et al., 2003) and thus engage in a peculiar relationship with the consolidated food system which is concurrently competitive and symbiotic. In building a moral and sustainable economy they compete with the dominant market structures, appropriating flows that would otherwise be channeled through corporate circuits of value creation. At the same time, for their exchange and reproduction needs they leverage on conventional market structures (Goodman et al., 2012). To maintain legitimacy, then, Mount (2012) suggests local and alternative food systems will have to preserve an alternative identity within a context of hybridity.

This poses a series of questions about their potential to scale up and out and deepen their impact on the wider food system. As the global financial and resources crises unfold, as Marsden and Franklin foresee (2013), it is likely that more voids and spaces will begin to open up for new post-neoliberal institutional platforms to take hold, which can favor the convergence of alternative food movements and empower them to become 'major social and political vehicles for embedding and creating the means of transitions to the post-neoliberal ecoeconomy' (ibid., p. 640). To grow, however, and engage more consumers and producers, local and alternative food networks must develop the ability to undermine the inertial forces of conventional food system and reconfigure routines, integrating new complexes of productionconsumption into the practices of daily life (Goodman et al., 2012). While avoiding the risks of 'dis-embedding' and 'de-localization' scaling-up processes imply, which may cause the loss of the distinctive local connection and 'regard' for the producers, such socio-ecological projects 
have to become assemblages of production-consumption practices, knowledge, routines and imaginaries, able to reconfigure the 'orderings' engendered by conventional agri-food (ibid.).

This calls for a 'reflexive' approach to governance, based on the continuous negotiation among a diversity of interests, interpretations and priorities, in which the focus is not on the shared goals and values, but on the process through which goals and values come to be shaped (Mount, 2012). To operate a truly food system reform within a context of neoliberalism - in which the state increasingly replaces older forms of welfare provision with more precarious, weaker and uneven forms (Amin et al., 2003) - a new food governance will have to overcome a host of regulatory constraints, whose nature reveals the productivist orientation that has guided food system governance so far. Most regulations, indeed, are designed to favor big operators and in many places produced the disappearance of local food infrastructures and facilities in the name of scale efficiencies and concentration (an example being the closure of most small and mediumsized town slaughterhouses in many parts of the EU), thus posing logistical barriers for small-scale producers' operations (Mount, 2012) ${ }^{11}$.

In conclusion, given this regulatory and hybrid operational context, in order to scale-up alternative food systems will need an open-governance structure, able to provide reflexivity, (re)negotiations of boundaries, flexibility, adaptation and responsiveness; directed towards creating and maintaining value, legitimacy and identity, carrying out open discussion between producers and consumers, and exposing to a broader audience the reasons for food system ecological reform and re-localization (Mount, 2012). A proper institutional building is therefore much needed, to create further institutional and interstitial space for the clustered agglomeration and crossover innovation in the convergent development of alternative food movements. In this direction, a novel institutional arrangement is taking shape in many cities of the global North, which are equipping themselves with innovative tools to create and sustain local food systems built around the notion

11 Mount and Andrée (2013) delineate four major areas of constraint of current food regulation in Northern countries that have to be addressed to foster convergence and scale improvements in alternative food systems. They refer to: rigidities on the application of health and safety legislation; inflexible definitions of land-uses classes; food blindness in existing zoning to food market developments; and temporary and ephemeral funding for food initiatives and infrastructure. Due to space limits we will not engage in further detailing such four spheres of regulatory constraint. of environmental, social and economic viability. In many localities, indeed, the adoption of urban food policies and the institutionalization of food policy councils are framing a municipal-based response to the distortions of the global food system. These novel policy instruments, we will argue, can play a role of facilitators in the development of an alternative to the conventional food system, and contribute to the overall sustainability of food provisioning.

\section{Urban food policy}

The most recent institutional innovation regarding the governance of food system is based in the city. It is brought by municipal governments which holistically conceive their city or regional food system as interconnected with many other urban functions, and manifest the intention to exert a power of coordination over its development. To do so, many cities are elaborating their own set of urban food policies, pursued through the adoption of urban food strategies and/or through the establishment of food policy councils. Alternative food networks seem to be naturally comprised within these promotion and regulation efforts, since their aims of inclusion and re-localization are deeply intertwined with city governments attempts to realize a better management of local foodscapes, directed to build a healthier and more just local food system.

The shifting regulatory role of cities, to which growing political power is attributed, is not a complete novelty. Many urban sociologists have testified the increasingly important role cities have assumed as political actors, as an effect of a 'neo-localist' regulatory scalar restructuring (Bagnasco, 1988; Trigilia, 1998). As Jessop (2002) asserts, local states are being reorganized as new forms of local and regional partnership to guide and promote the development of local and regional resources, and cities have become important nodes and nexus of political arrangements in shepherding economic regulation and coordinating interests among diverse groups of actors. City- and regional-level governments are becoming more and more crucial in promoting new forms of public intervention, which is concretized through the formulation of urban and economic policies (Le Galés, 1998) that do not only take into account the market forces that shape the economic relations, but also reckon the geographical proximity where these relations are integrated by extraeconomic factors, such as cooperation and reciprocity (Pichierri, 2002).

Food regulation is not an exception, since a foremost policy option to counteract the inequality- 
and insecurity-producing forces of current food system is emanating from cities, in the form of urban food policies (UFP). Since the 80s, cities have come to recognize the important role local governments can play in addressing food security and its relations to sustainable agriculture (Feenstra, 1997). Notwithstanding, it is now that, once the exposure to the effects of the food crisis has caused the previously incumbent 'consumers-government-industrial food alliance' to break, to use the words of Goodman et al. (2014), more than ever urban consumers are seeking new allies. As a result, local food strategies are brought to the fore and increasingly implemented by local institutions. Throughout the world, pioneering city governments are beginning to see themselves as food system players on the national and international scene, creating new forms of connectivity across urban and rural landscapes by forging new alliances between food producers and consumers. This gives cities a scope for becoming important centers of change in the food system and contribute to the sustainable food paradigm (Sonnino and Spayde, 2014), in line with what the FAO (2011) recognizes as a new paradigm of ecosystem-based, territorial food system planning, whose aim is not to replace global food supply chain but to improve the local management of food systems, that the FAO acknowledges to be concurrently global and local.

Although a number of urban organizations involved in the city's food system have long existed, for many years urban food governance has been addressed with a piecemeal approach, with organization often pursuing separate paths and the various public institutional branches following different short-term or short-sighted projects (Pothukuchi and Kaufman, 1999). The need for a policy coordination effort regarding food has been expressed even at the governmental level. For instance, as Tim Lang and his colleagues report (Lang et al., 2005, p.11), the UK House of Commons' Health Committee's report on obesity, published in 2004, concluded that 'national food and health policy lacked coherence, integration and effectiveness' and UK consumer bodies began to lobby for the establishment of a food policy council at the national level.

As a counterweight to such piecemeal approach, we are recently witnessing the rise of a new urban food policy and planning approach that aims to address the new food security challenges in a more structural, systemic and place-based way, implementing two novel instruments: food policy councils and urban food strategies.

\section{Food policy councils and urban food strategies}

Aiming at facilitating the creation of a comprehensive food system policy framework improving public health and the general quality of life (Muller et al., 2009), food policy councils (FPCs) are, in the words of Sonnino and Spayde (2014, p. 189), 'organization[s] of people who are endowed with a mandate and, at least ideally, the power and the authority to effect food system change through the design of policies that integrate food with other policy areas - including health, the environment, transport and antipoverty'. Their efforts are directed towards setting a policy level coherence and communication ground between various governmental functions to catalyze policy formation. Interestingly, policy implementation appears to be not included, since it remains within the pre-existing political administrative framework. For Sonnino and Spayde (ibid.), one of the most innovative features of FPCs is their heavy reliance on the involvement of civil society (environmental organizations, food movements, NGOs, consumer organizations, retailers, cooks, shopkeepers and many other food system stakeholders), and that they interestingly represent, at least partly, a bottom-up response to the failure of national and global policies.

Analyzing the emerging literature on the topic, the scholars detect four basic functions of FPCs (ibid.). The first is to give advice and provide research and information about background scenario, identification of problems, evaluation of solutions, definition of potential policies fit for the specific city context, and monitoring of progress and implementation. The second deals with encouraging change in the food system mobilizing relevant organizations, providing policies, standards and funding opportunities. As a third aspect, FPCs should engage with stakeholders to promote networking between different stakeholders, policy makers and organizations, involving large business, advocating and building consensus on food issues among the stakeholders involved, and eventually mediating when necessary. Lastly, they are seen able of educating the public about the issues and the possible solutions, providing policy learning and promoting youth education, aiming at the creation of the necessary cultural context for ensuring lasting policy changes. In addition, drawing on Le Galés (1998) we might argue that FPCs could carry out the crucial task of providing institutional legitimation of discourses and practices around food, that could influence or even expedite the policymaking process at a national scale.

Being complementary to FPCs, urban food strategies (UFSs) refer to documents (such as food charters and 
plans) containing a vision statement and action plans, indicators or strategies, allowing cities to monitor changes and progress in the transition towards a more sustainable urban/regional food system, usually manifesting a concrete willingness to help regional farmers, leverage on food to improve public health, and create new and more sustainable connections between urban, periurban and rural environments (Sonnino, 2009b; Marsden and Sonnino, 2012). Their aim is to create synergies and coherence (Brunori and Rossi, 2000) among a variety of activities and roles within the city and between the city and its surrounding rural hinterland.

Existing examples of urban food policies suggest re-localizaton is generally pursued as a crucial strategy to the achievement of city food objectives (Sonnino and Spayde, 2014). In addition, an emerging body of empirical work on the topic suggests the existence of a set of common principles and features that shape the nature of these new policy instruments. The already cited push to re-localization, in fact, combines with a specific attention to farming methods, fair labor practices, environmental indicators and animal welfare, in the pursuit of three main (and shared) objectives: justice and rights over food (Lang et al., 2005; Friedmann, 2007; Wiskerke, 2009), control of the food chain (Welsh and McRae, 1998; Caraher and Coveney, 2004), and environmental conservation (Lang et al. 2005; Wiskerke, 2009; Morgan and Sonnino, 2010). Many urban food policies have a strong focus on justice and rights, including the right to have access to food and the principles of food citizenship, food insecurity and social justice. Many strategies attached to this new urban food governance aim at taking food chain control back from the global corporate, addressing the local de-skilling, isolation, and loss of market opportunities for the local provisioning sector caused by the global food system. Lastly, UFPs often prioritize local agriculture as a way to promote environmental conservation, usually protecting agricultural land, including for environmental and cultural heritage reasons, and address issues of food waste and losses.

\section{The potential for guiding alternative food networks' development}

If such whole of guiding principles is a common denominator of the emerging urban food institutional arrangements, then the strand that binds these with the alternative food networks, and to the bottom-up response to the incumbent food crisis the latter represent, appears inevitably short. In the way they are conceptualized, urban food policies appear to offer a potential in facilitating scale and scope development of alternative food systems. Both indeed, at least rhetorically, embrace the complexity of the food system, that involves integrating ecology and social thinking (Lang, 2005), dismissing the individualistic, linear and mechanistic thinking that emphasizes consumer choices, and which ultimately distracts attention from the real determinants of food insecurity, such as history, class, gender, income, ethnicity, affordability and global supply patterns (Caraher and Coveney, 2004). Urban food policies and alternative food networks appear as the two sides of the same coin, both products of the general recognition of the unsustainability attached to the food system, and both intended to generate mechanisms to cope with those 'failures of coordination' (Lang et al., 2005) that created the space for a corporate-controlled productivist model to establish as the only available development paradigm for the food system.

AFNs' major weakness is to be found in the difficulties they face in involving ever greater numbers of people into the contingent process of social learning and innovation that aim to 'normalize' novel patterns of productionconsumption, with their distinctive material, cultural and moral economies, into the practices and routines of daily life (Goodman et al., 2012). In a sector dominated by very attentive and dynamic corporations, keen on strategically appropriating even the latest alternative conceptual resource if it is susceptible of market exploitation, the diffusion of AFNs as organizational expressions of recursive material and symbolic interaction between production and consumption will need producers and consumer to acquire knowledge and skills, both new and revived. Food movements and initiatives will need support, in communicating their message as well as organizing their practice. The coordination potential and the declared objectives of the urban food policies which are spreading throughout the world seem to act in the same direction, thus coming to represent the most innovative instruments to facilitate the transition towards a local and sustainable food system. As commented by Marsden and Franklin (2013, p.639), the growth of city food councils reflects the "need to tackle the scalar politics of institutional rigidity, blindness and inertia with regard to the potential convergence and scaling out of alternative food movements'.

Reviewing what food policy scholars consider to be the most common functions and operational instruments cities are relying on to implement their urban food policies will give us a hint to try and illustrate the tight relationship that can exist between these and the development of alternative food initiatives. 
Food policy councils and strategies play a key role as networking actors: they can create 'new links and new relationships between different stages and actors of the food chain' (Sonnino, 2009a, p. 431), operating as networkers and facilitators across the spectrum of the food system to increase the implementation capacity of other organizations (Schiff, 2008), facilitate dialogue (Blay-Palmer, 2009), bring together stakeholders (Kim and Blanck, 2011) and create avenues for alliances and lobbying (Caraher and Covenay, 2004) - especially if they are effectively resourced and include members representing different interests and expertise. Many AFN initiatives or ecological projects, which are often scattered over the territory and involve small numbers of people, lack the capacity to interact and/ or agglomerate into larger territorial clusters. A stronger network of alternative projects within a city or a region can help overcoming the barriers to participation for both the consumers and the producers. Individuals interested in consuming local or sustainable food may find easier access to a more complete range of foods obtained through alternative sources, thus enjoying the possibility of reducing the dependence on supermarkets for their food purchasing routines; while farmers or manufacturers willing to cater responsibly-produced food through a shorter chain may find easier access to a critical mass of customers to reach through alternative channels, thus enjoying the possibility of reducing their dependence on conventional supply operators.

Another function UFPs are expected to perform is to help organizations to gain political capital and credit for the food projects they are involved in. It proves crucial especially for alternative, non-profit, disadvantaged or neighborhood food organizations that chronically suffer from lack of political empowerment. This fits within the framework depicted by Le Galès, who explains the growing role of the political in local regulation not in a dominating sense but in the sense of mobilizing and organizing interests so that new regulations can be defined within the framework of a collective plan (Le Galès, 1998). Additionally, such policy approach recognizes the need to enhance what different groups who have similar goals are doing, rather than having them competing (Schiff, 2008). This promises to realize that 'reflexive localism' Goodman and his colleagues (2012) advocate for a proper governance of alternative food systems. It involves a reflexive and processual understanding of local food politics and food justice, articulated as an open, process-based and inclusive vision to lead the discussion about what a just food system would look like, whose ultimate challenge is to discover practices that make society 'better' without reinforcing inequalities (ibid.).
A certain contribution to the social construction of food security and sustainability issues is also deemed to be one of the effects of the implementation of UFPs. They can provide a platform where food issues and problems are made more visible. Charles Wright Mills (1959) argues that a problem is not perceived as a 'social problem' to be addressed collectively by society if it is not presented as such. This is particularly true for food-related problems, such as diet-related diseases, food access and food choices, which are commonly perceived as individual problems, personal issues of choice and knowledge, scarcely related to the underlying cultural and economic structure. That is why the role of 'raising the visibility of a broad spectrum of food system interests in government policy, planning and decision-making activities' (Schiff, 2008, p. 216) is of great importance because it helps to incorporate in the collective conscious of the city ideas of justice, health and support for the struggling and marginalized small local farmers. It potentially boosts a double process affecting the ability of AFNs to strengthen their impacts: on the one side, by directly conferring legitimization to alternative movements and endorsing advocacy discourses over foodrelated concerns, it facilitates the development of new or larger alternative groups and activities; on the other side, by fostering public education over those same concerns, it contributes in promoting the public health agenda and set the ground for a broader participation to food citizenship revindication initiatives.

From an operational standpoint, there are three types of public intervention that are increasingly levered to concretize an integrated food policy approach: infrastructural development, spatial planning, and public procurement. Infrastructures can be developed to satisfy the need for reconnecting local food producers with urban consumers through the creation, for instance, of alternative retail outlets like farmers' markets, neighborhood markets and CSA schemes, or regional food hubs and permanent wholesale markets. Providing such facilities goes in the direction of removing the logistical and operational obstacles to the upscaling and convergence of AFNs.

Spatial planning can also facilitate the production and distribution of local foods in urban areas and help re-regulating other aspects of the urban foodscape (Sonnino and Spayde, 2014), through supportive land ordinances that protect the accessibility of food retail outlets, discourage food waste or unhealthy consumption habits. An example of the latter is detectable in London, where many boroughs have successfully banned fast food outlets from areas adjacent to schools (ibid.). Furthermore, urban land zoning can be responsible for the development of urban agriculture, a community-based food production 
model which is gaining ever greater vibrancy in many metropoles all over the world.

A third and last strategic option cities have at their disposal is public procurement. Steering public food purchases towards local, environmentally-friendly and healthy sources realizes a direct intervention in the regional economy, contributes to public health and, is argued, fosters collaboration between urban communities and food producers, processors and suppliers located within and around the city. Through food procurement, for instance, city institutions can favor small-scale, local and ecological food suppliers, with the dual effect of providing healthier meals to individuals (especially to those most exposed to health risk, such as kids at school or hospital guests) and to distract money from the mainstream global system, thus reinforcing the local economic fabric and strengthening the relations between regional producers and urban areas. By also attaching an educational dimension, then, these renewed procurement choices can stimulate a wider collaborative relationship, involving numerous food system stakeholders (like local food advocates, anti-waste or healthy-eating movements, and many more) and embark in an open discussion about food production-consumption patterns and their consequences over health, society, economy, and the environment.

\section{Conclusions}

Urban food policies, as they are currently being conceptualized and implemented all over the world, emphasize a new, multifunctional vision of food, stressing the need to enhance networking within and between food systems and give visibility to food-related socio-economic issues and problems. Given these characteristics, they can provide a context for alternative food networks to increase their relevance as agents advancing food system reformation, even though such concrete ability is still to be tested and much research is needed to monitor and evaluate future developments in the field.

Operating a paradigm change in the food system will require a complex interaction of factors. To achieve the sustainability goal, the multitude of actors to a varying extent involved in the production, distribution, promotion and consumption of food must jointly and coordinately operate to provide an opportunity for recalibrating lifestyles and food-related routines. In addition, this will need to be matched by a strong education effort, aimed at creating the cultural basis for a renewed relationship with food to take place, together with a favorable legislation to facilitate such developments. An effective partnership between consumers, producers, institutions and civil society is therefore much sought after.

The consolidation of alternative food systems is a promising link of this new food chain. Despite the vibrancy they have gained over the last years, we still cannot express a judgment about their ability to lead a radical transformation of the 'world of food', rather than being just a part of its reforming process or - on the opposite - whether they will produce no long-term effect on the food provisioning system. It is a matter worth attention, as compelling is the need to reflect about food and its implications in the world's physical, social and cultural resources, a subject all the time more relevant in current society.

\section{References}

Allen, P. (2010). Realizing justice in local food systems. Cambridge Journal of Regions, Economy and Society, 3, 295-308.

Almås, R., \& Campbell, H. (2012). Rethinking agricultural policy regimes: food security, climate change and the future resilience of global agriculture (Vol. 18). Emerald Group Publishing.

Amin, A., Cameron, A., \& Hudson, R. (2003). The alterity of the social economy. In Leyshon, A., Lee, R., \& Williams, C. C. (Eds.). (2003). Alternative economic spaces. Sage. London. 27-54.

Bagnasco, A. (1988). La costruzione sociale del mercato. Il Mulino. Bologna.

Blay-Palmer, A. (2009). The Canadian pioneer: The genesis of urban food policy in Toronto. International Planning Studies, 14(4), 401-416.

Born, B., \& Purcell, M. (2006). Avoiding the local trap scale and food systems in planning research. Journal of Planning Education and Research, 26(2), 195-207.

Brown, C., \& Miller, S. (2008). The impacts of local markets: a review of research on farmers markets and community supported agriculture (CSA). American Journal of Agricultural Economics, 90(5), 1298-1302.

Brunori, G., \& Rossi, A. (2000). Synergy and coherence through collective action: some insights from wine routes in Tuscany. Sociologia ruralis, 40(4), 409-423.

Caraher, M., \& Coveney, J. (2004). Public health nutrition and food policy. Public health nutrition, 7(05), 591-598.

FAO (1997). Report of the World Food Summit - Rome 1996.

FAO (2011). Food, Agriculture and Cities: Challenges of food and nutrition security, agriculture and ecosystem management in an urbanizing world. FAO Food for the Cities multi-disciplinary initiative position paper. Rome.

Feagan, R. (2007). The place of food: mapping out the 'local'in local food systems. Progress in human geography, 31(1). 23-42.

Feenstra, G. W. (1997). Local food systems and sustainable communities. American journal of alternative agriculture, 12(01), 28-36.

Franklin, A., \& Morgan, S. (2014). Exploring the new rural-urban interface: community food practice, land access and farmer entrepreneurialism. In Marsden, T., \& Morley, A. (Eds.). 
(2014). Sustainable food systems: building a new paradigm. Routledge. London. 166-185.

Friedmann, H. (2007). Scaling up: Bringing public institutions and food service corporations into the project for a local, sustainable food system in Ontario. Agriculture and Human Values, 24(3), 389-398.

Godfray, H. C. J., Beddington, J. R., Crute, I. R., Haddad, L., Lawrence, D., Muir, J. F., ... \& Toulmin, C. (2010). Food security: the challenge of feeding 9 billion people. Science, 327(5967), 812-818.

Goodman, D., DuPuis, E. M., \& Goodman, M. K. (2012). Alternative food networks: Knowledge, practice, and politics. Routledge.

Hinrichs, C. C. (2003). The practice and politics of food system localization. Journal of rural studies, 19(1), 33-45.

IAASTD (International Assessment of Agricultural Knowledge, Science and Technology for Development). (2009). Agriculture at a crossroads. Global Report.

Ilbery, B., Maye, D., Kneafsey, M., Jenkins, T., \& Walkley, C. (2004). Forecasting food supply chain developments in lagging rural regions: evidence from the UK. Journal of Rural Studies, 20(3), 331-344.

Jessop, B. (2002). Liberalism, neoliberalism, and urban governance: A state-theoretical perspective. Antipode, 34(3), 452-472.

Kim, S. A., \& Blanck, H. M. (2011). State legislative efforts to support fruit and vegetable access, affordability, and availability, 2001 to 2009: a systematic examination of policies. Journal of Hunger \& Environmental Nutrition, 6(1), 99-113.

Kirwan, J. (2004). Alternative strategies in the UK agro-food system: interrogating the alterity of farmers' markets. Sociologia ruralis, 44(4), 395-415.

Kneafsey, M., Cox, R., Holloway, L., Dowler, E., Venn, L., \& Tuomainen, H. (2008). Reconnecting consumers, producers and food: exploring alternatives. Berg. New York.

La Trobe, H. (2001). Farmers' markets: consuming local rural produce. International Journal of Consumer Studies, 25(3), 181-192.

Lang, T. (2005). Food control or food democracy? Re-engaging nutrition with society and the environment. Public Health Nutrition, 8(6a), 730-737.

Lang, T., Rayner, G., Rayner, M., Barling, D., \& Millstone, E. (2005). Policy Councils on Food, Nutrition and Physical Activity: the UK as a case study. Public Health Nutrition, 8(1), 11-19.

Le Galès, P. (1998). Regulations and governance in European cities. International journal of urban and regional research, 22(3), 482-506.

Lee, R. G., \& Stokes, E. (Eds.). (2009). Economic globalization and ecological localization: socio-legal perspectives. WileyBlackwell.

Leyshon, A., Lee, R., \& Williams, C. C. (Eds.). (2003). Alternative economic spaces. Sage. London.

Little, J., Ilbery, B., \& Watts, D. (2009). Gender, consumption and the relocalisation of food: A research agenda. Sociologia Ruralis, 49(3), 201-217.

Marsden, T., \& Franklin, A. (2013). Replacing neoliberalism: theoretical implications of the rise of local food movements. Local Environment, 18(5), 636-641.

Marsden, T., \& Morley, A. (Eds.). (2014). Sustainable food systems: building a new paradigm. Routledge. London.

Marsden, T., \& Sonnino, R. (2012). Human health and wellbeing and the sustainability of urban-regional food systems. Current Opinion in Environmental Sustainability, 4(4), 427-430.
Maye, D., \& Kirwan, J. (2013). Food security: A fractured consensus. Journal of Rural Studies, (29), 1-6.

Mills, C. W. (1959). The sociological imagination. Oxford University Press. Oxford.

Morgan, K., \& Sonnino, R. (2010). The urban foodscape: world cities and the new food equation. Cambridge Journal of Regions, Economy and Society, rsq007.

Morris, C., \& Buller, H. (2003). The local food sector: a preliminary assessment of its form and impact in Gloucestershire. British Food Journal, 105(8), 559-566.

Mount, P. (2012). Growing local food: scale and local food systems governance. Agriculture and Human Values, 29(1), 107-121.

Mount, P., \& Andrée, P. (2013). Visualising community-based food projects in Ontario. Local Environment, 18(5), 578-591.

Muller, M., Tagtow, A., Roberts, S. L., \& MacDougall, E. (2009). Aligning food systems policies to advance public health. Journal of Hunger \& Environmental Nutrition, 4(3-4), 225-240.

Pichierri, A. (2002). La regolazione dei sistemi locali: attori, strategie, strutture. II Mulino. Bologna.

Pothukuchi, K., \& Kaufman, J.L. (1999). Placing the food system on the urban agenda: The role of municipal institutions in food systems planning. Agriculture and Human Values, 16, 213-224.

Roberts, W. (2008). The no-nonsense guide to world food. New Internationalist.

Sage, C. (2011). Environment and food. Routledge. London.

Santini, F., \& Gomez y Paloma, S. (Eds.). (2013). Short Food Supply Chains and Local Food Systems in the EU: a state of play of their socio-economic characteristics. Publications Office.

Schiff, R. (2008). The role of food policy councils in developing sustainable food systems. Journal of Hunger \& Environmental Nutrition, 3(2-3), 206-228.

Sonnino, R. (2009a). Feeding the city: Towards a new research and planning agenda. International Planning Studies, 14(4), 425-435.

Sonnino, R. (2009b). Quality food, public procurement, and sustainable development: the school meal revolution in Rome. Environment and Planning A, 41(2), 425-440.

Sonnino, R., \& Spayde, J. J. (2014). The new frontier? Urban strategies for food security and sustainability. In Marsden, T., \& Morley, A. (Eds.). (2014). Sustainable food systems: building a new paradigm. Routledge. London. 186-207.

Spaargaren, G., Oosterveer, P., \& Loeber, A. (Eds.). (2013). Food practices in transition: changing food consumption, retail and production in the age of reflexive modernity. Routledge.

Tregear, A. (2011). Progressing knowledge in alternative and local food networks: critical reflections and a research agenda. Journal of Rural Studies, 27(4), 419-430.

Trigilia, C. (1998). Sociologia economica: stato, mercato e società nel capitalismo moderno. II Mulino. Bologna.

Welsh, J., \& MacRae, R. (1998). Food citizenship and community food security: lessons from Toronto, Canada. Canadian Journal of Development Studies/Revue canadienne d'études du développement, 19(4), 237-255.

Winter, M. (2003). Embeddedness, the new food economy and defensive localism. Journal of rural studies, 19(1), 23-32.

Wiskerke, J. S. (2009). On places lost and places regained: Reflections on the alternative food geography and sustainable regional development. International planning studies, 14(4), 369-387. 